\title{
Ammonothermal Synthesis and Photocatalytic Activity of Lower Valence Cation-Doped $\mathrm{LaNbON}_{2}$
}

\author{
Chihiro Izawa, ${ }^{1,2}$ Takeshi Kobayashi, ${ }^{1}$ Kazuhisa Kishida, ${ }^{1}$ and Tomoaki Watanabe \\ ${ }^{1}$ Department of Applied Chemistry, School of Science and Technology, Meiji University, 1-1-1 Higashi-Mita, Tama-ku, \\ Kawasaki-shi, Kanagawa 214-8571, Japan \\ ${ }^{2}$ Japan Society for the Promotion of Science, Kanagawa 214-8571, Japan \\ Correspondence should be addressed to Tomoaki Watanabe; tomowata@meiji.ac.jp
}

Received 24 September 2014; Revised 12 December 2014; Accepted 12 December 2014; Published 25 December 2014

Academic Editor: Markku Leskela

Copyright (C) 2014 Chihiro Izawa et al. This is an open access article distributed under the Creative Commons Attribution License, which permits unrestricted use, distribution, and reproduction in any medium, provided the original work is properly cited.

\begin{abstract}
Highly crystalline pure perovskite-type $\mathrm{LaNbON}_{2}$ powders were synthesized in supercritical ammonia using sodium hydroxide as an oxygen source. Additionally, doping $\mathrm{LaNbON}_{2}$ with cations of lower valence than that of the parent cation was performed to inhibit reduction of $\mathrm{Nb}^{5+}$. Various characterization methods indicated that crystallinity, particle morphology, and absorption edge of the product, that is, the factors possibly affecting photocatalytic activity, were not significantly changed by the doping of a lowervalence cation. Nevertheless, the doped $\mathrm{LaNbON}_{2}$ synthesized using the ammonothermal method evolved hydrogen, suggesting that this type of doping decreases the formation of reduced niobium species and consequently enhances the photocatalytic activity of $\mathrm{LaNbON}_{2}$. In case of doped $\mathrm{LaNbON}_{2}$ synthesized using conventional method, no hydrogen evolution was observed. This

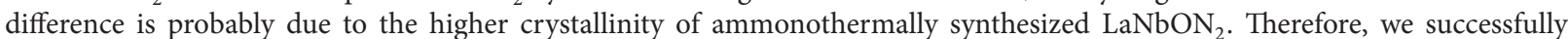
produced $\mathrm{LaNbON}_{2}$ with improved potential for photocatalytic activity for hydrogen evolution under visible light irradiation using ammonothermal synthesis and lower-valence cation doping.
\end{abstract}

\section{Introduction}

The conversion of solar energy into chemical energy is an attractive technology for sustainable energy systems. An ideal system for this conversion is photocatalytic water splitting using sunlight as a light source to directly produce hydrogen and oxygen from water. For visible light, active water-splitting photocatalysts are desirable for the efficient conversion of solar energy into hydrogen [1]. Recently, (oxy)nitrides containing transition metal cations with empty d orbitals, such as $\mathrm{Ti}^{4+}, \mathrm{Zr}^{4+}, \mathrm{Nb}^{5+}$, or $\mathrm{Ta}^{5+}$, have been reported as potentially visible-light-driven photocatalysts $[2,3]$. The potential energies of the valence band edges composed of N2p orbitals are higher than those of $\mathrm{O} 2 \mathrm{p}$ orbitals, resulting in narrower band gap energies of (oxy)nitrides. Additionally, niobiumbased oxynitrides have a wide visible light absorption band $[3,4]$. Therefore, the target of this research is $\mathrm{LaNbON}_{2}-\mathrm{a}$ niobium based oxynitride with a perovskite structure and a band gap energy of $1.6 \mathrm{eV}$-which is among the smallest band gap energy values reported for oxynitrides [5]. Perovskitetype material $\mathrm{LaTaON}_{2}$, with a similar crystal structure to $\mathrm{LaNbON}_{2}$ and a band gap energy of $1.9 \mathrm{eV}$, demonstrates photocatalytic activity for hydrogen evolution under visible light irradiation [6, 7]. Therefore, $\mathrm{LaNbON}_{2}$ is expected to exhibit similar photocatalytic activity. However, in previous studies of this material, no water reduction or oxidation activity under visible light irradiation has been observed [4]. One plausible explanation for this report is that the small band gap of $\mathrm{LaNbON}_{2}$ decreases the driving force for redox reactions. Additionally, $\mathrm{LaNbON}_{2}$ contains nitrogen vacancies due to calcination at long durations and high heating temperatures relative to the decomposition temperature of oxynitride $[4,8] . \mathrm{Nb}^{5+}$ is reduced to lower oxidation state species for charge compensation of the nitrogen vacancies. These reduction species form a donor level just below the bottom of the conduction band, which may act as a recombination center of excited electrons and electron holes, leading to negligible activity [9]. There are two key requirements for the 
enhanced photocatalytic activity of $\mathrm{LaNbON}_{2}$ : the inhibition of $\mathrm{LaNbON}_{2}$ decomposition resulting from calcination and the inhibition of reduced niobium species formation.

The two techniques, an ammonothermal method and cation-doping using lower valence than that of the parent cation, were employed to develop photocatalytic activity in $\mathrm{LaNbON}_{2}$. The ammonothermal method is a process for synthesizing (oxy)nitride materials in supercritical ammonia. This method has been successfully used to synthesize GaN [10], $\mathrm{CaAlSiN}_{3}$ [11, 12], and $\mathrm{LaTaON}_{2}$ [13]. The important advantages of the ammonothermal method over conventional methods are the high crystallinity of (oxy)nitrides at low temperatures and the suppression of defect formation. Doping with cations of lower valence than that of the parent cation intentionally introduces anion vacancies that scavenge reduced transition metal cation species. It has been reported that the lower-valence cation doping in perovskite-type $\mathrm{SrTiO}_{3}$, a photocatalyst for overall water splitting under UV irradiation, effectively enhances the photocatalytic activity for water splitting [14]. Therefore, a similar effect is expected to exist in $\mathrm{LaNbON}_{2}$.

Using these techniques, we studied their effects on the crystallinity, morphology, optical properties, and photocatalytic activity of the products.

\section{Materials and Methods}

2.1. Synthesis of $\mathrm{LaNbON}_{2}$ by Ammonothermal Method. The starting alloy $(\mathrm{La}: \mathrm{Nb}=2: 1)$ was prepared by the arc discharge melting of La (99.9\%, Kojundo Chemical Lab., Japan) and $\mathrm{Nb}$ (99.9\%, Kojundo Chemical Lab., Japan) powders. For the synthesis of lower valence cation-doped $\mathrm{LaNbON}_{2}$, the starting alloy (La: $\mathrm{Sr}: \mathrm{Nb}=1.9: 0.1: 1$ or $\mathrm{La}: \mathrm{Nb}: \mathrm{Ti}=$ $2: 0.95: 0.05)$ was prepared through a similar process using Sr (99.9\%, Kojundo Chemical Lab., Japan) and Ti (99.9\%, Kojundo Chemical Lab., Japan) powders. The prepared alloy was ground with a sample mill in an argon atmosphere. The ground alloys $\mathrm{NaNH}_{2}$ (95\%, Aldrich, U.S.A.) and $\mathrm{NaOH}$ (97\%, Junsei Chemical, Japan) were mixed in molar ratios of $\mathrm{Nb}: \mathrm{NaNH}_{2}: \mathrm{NaOH}=1: 5: 2$ and loaded in a bottom-sealed $\mathrm{Ni}$ tube. The nickel tube was transferred to a vertically positioned high-pressure vessel, which was then filled completely with anhydrous liquid ammonia (99.999\%, Taiyo Nippon Sanso, Japan) via a cooled condenser. The pressure vessel was heated to $573 \mathrm{~K}$ at a rate of $5 \mathrm{~K} \mathrm{~min}^{-1}$ for $20 \mathrm{~h}$ and then heated to $1073 \mathrm{~K}$ at a rate of $1 \mathrm{~K} \mathrm{~min}^{-1}$ for $5 \mathrm{~h}$ with an ammonia pressure of $100 \mathrm{MPa}$. The obtained sample was exposed to air and washed several times with water, ethanol, and diluted chloric acid to remove sodium amide and $\mathrm{La}(\mathrm{OH})_{3}$. The sample was then dried at $343 \mathrm{~K}$ for $6 \mathrm{~h}$ in air.

2.2. Synthesis of $\mathrm{LaNbON}_{2}$ by Conventional Method. A reference sample of $\mathrm{LaNbON}_{2}$ was synthesized using the conventional method of nitridation of a $\mathrm{LaNbO}_{4}$ oxide precursor, which was prepared by solid-state synthesis [15]. $\mathrm{La}_{2} \mathrm{O}_{3}$ (>99.5\%, Wako Pure Chemical, Japan) and $\mathrm{Nb}_{2} \mathrm{O}_{5}$ (>99.5\%, Kojundo Chemical Lab., Japan) were mixed in a stoichiometric ratio by wet milling. For the synthesis of lower valence cation-doped $\mathrm{LaNbON}_{2}$, oxide precursor ( $\mathrm{La}: \mathrm{Sr}: \mathrm{Nb}$
$=0.95: 0.05: 1$ or $\mathrm{La}: \mathrm{Nb}: \mathrm{Ti}=1: 0.95: 0.05)$ was prepared through a similar process using $\mathrm{SrCO}_{3}$ (99.9\%, Kojundo Chemical Lab., Japan) and $\mathrm{TiO}_{2}$ (99.9\%, Kojundo Chemical Lab., Japan) powders. To this mixture, $\mathrm{NaCl}(>99.5 \%$, Wako Pure Chemical, Japan) and $\mathrm{KCl}$ (>99.5\%, Wako Pure Chemical, Japan) were added in equimolar quantities as mineralizers, and the sample was calcined in air at $1473 \mathrm{~K}$ for $12 \mathrm{~h}$. The product was washed with deionized water in an ultrasonic bath to remove the halides and then dried at $343 \mathrm{~K}$ for $6 \mathrm{~h}$ in air. $\mathrm{LaNbON}_{2}$ powder was obtained by nitridation of the oxide precursor at $1223 \mathrm{~K}$ for $15 \mathrm{~h}$ under flowing ammonia (99.999\%, Showa Denko, Japan).

2.3. Characterizations. The crystal structure of the product was determined using powder X-ray diffraction (XRD, Rint2200, Rigaku, Japan) with $\mathrm{Cu} K \alpha$ radiation. Particle sizes and morphologies were determined using field emission scanning electron microscopy (FE-SEM, S-5200, Hitachi, Japan). Optical properties were determined using ultravioletvisible diffuse reflectance spectra (UV-Vis DRS, JascoV-550 spectrometer, Japan). Photocatalytic activities for hydrogen evolution from an aqueous methanol solution under visible light irradiation were measured using a closed gas circulation system. This system consisted of a Pyrex top-irradiation type cell in which methanol was used as a sacrificial electron donor. $0.1 \mathrm{~g}$ of the sample was dispersed in $10 \mathrm{vol} . \%$ methanol solution $(100 \mathrm{~mL})$ containing $\mathrm{H}_{2} \mathrm{PtCl}_{6} \cdot 6 \mathrm{H}_{2} \mathrm{O}$. Pt was photodeposited on the $\mathrm{LaNbON}_{2}$ in situ using $\mathrm{H}_{2} \mathrm{PtCl}_{6} \cdot 6 \mathrm{H}_{2} \mathrm{O}$ as the precursor and the suspension was irradiated by a $70 \mathrm{~W}$ ceramic metal halide lamp $(\lambda>380 \mathrm{~nm})$. The evolved gas was analyzed by gas chromatography (GC-8A, TCD, Ar carrier gas, Shimadzu, Japan).

\section{Results and Discussion}

Figure 1 shows XRD patterns of the products synthesized by the ammonothermal and the conventional methods. All diffraction peaks are attributed to perovskite-type $\mathrm{LaNbON}_{2}$. Ammonothermally synthesized $\mathrm{LaNbON}_{2}$ has higher crystallinity than that synthesized by the conventional method because $\mathrm{LaNbON}_{2}$ particles grow by dissolutionrecrystallization processes in ammonia under supercritical conditions. The crystallite sizes, calculated by Scherrer's equation, are $33.9 \mathrm{~nm}$ (ammonothermal method) and $24.7 \mathrm{~nm}$ (conventional method). The crystal structure characterization therefore indicates that highly crystalline $\mathrm{LaNbON}_{2}$ was synthesized in supercritical ammonia at low temperatures. In ammonothermal synthesis of $\mathrm{LaTaON}_{2}$, addition of oxygen species is unnecessary because the moisture occurring as impurities in air or reagents supplies a sufficient amount of oxygen [13]. In this study, water in the ammonia was removed via a cooled condenser, and sodium hydroxide was instead used as an oxygen source to quantify the amount of added oxygen. Sodium hydroxide was chosen as an oxygen source because $\mathrm{NaNH}_{2}$ reacts with water to form $\mathrm{NaOH}$. Furthermore, XRD patterns indicated that when an insufficient amount of $\mathrm{NaOH}$ was added, the resulting products were nitride and hydride of niobium. Therefore, it was determined 


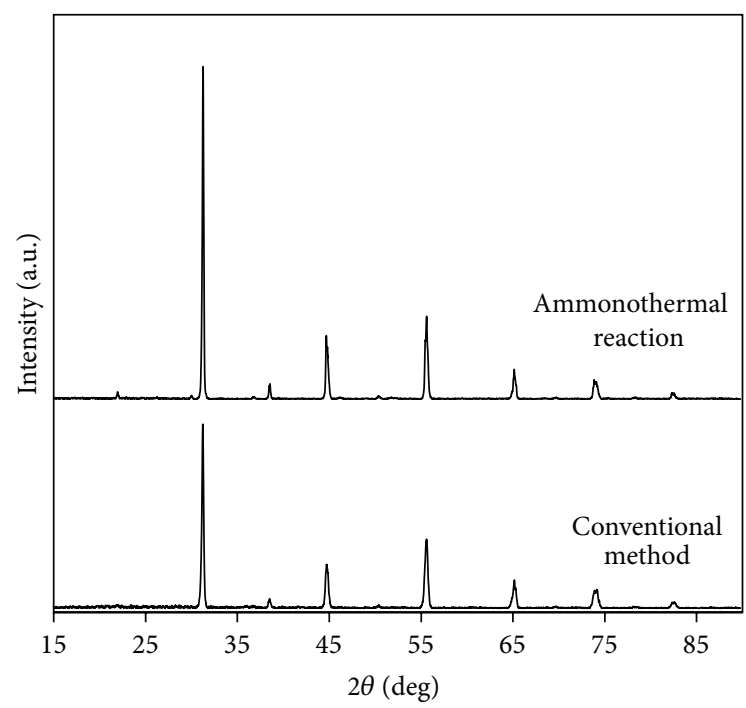

FIGURE 1: XRD patterns of products synthesized by the ammonothermal method and by the conventional method.

that the addition of $\mathrm{NaOH}$ induces the formation of phasepure $\mathrm{LaNbON}_{2}$ via the ammonothermal method.

$\mathrm{LaNbON}_{2}$ doped with $\mathrm{Sr}^{2+}(5 \%)$ and $\mathrm{Ti}^{4+}(5 \%)$ was synthesized using the ammonothermal method to produce lower valence cation-doped $\mathrm{LaNbON}_{2}$. In the XRD patterns for these materials (Figure 2), all diffraction peaks are attributed to perovskite-type $\mathrm{LaNbON}_{2}$, with no additional diffraction peaks from impurities. The crystallinity and the crystallite size were not significantly changed by doping.

In the XRD patterns for lower valence cation-doped and undoped $\mathrm{LaNbON}_{2}$ synthesized by conventional method, all diffraction peaks are attributed to perovskite-type $\mathrm{LaNbON}_{2}$, with no additional diffraction peaks from impurities. The crystallinity and the crystallite size were not significantly changed by doping.

SEM images of $\mathrm{LaNbON}_{2}$ synthesized using the ammonothermal and the conventional methods are shown in Figure 3. The ammonothermally synthesized $\mathrm{LaNbON}_{2}$ powder consists of dispersed cubic particles, which further indicates high crystallinity [6], supporting the interpretation of the XRD analysis. The particle morphology of the product was not significantly affected by doping. The particle size of ammonothermally synthesized $\mathrm{LaNbON}_{2}$ was $1-2 \mu \mathrm{m}$, while the powder synthesized by nitridation of the oxide precursor consists of agglomerated particles with a particle size of $0.2-1 \mu \mathrm{m}$. This result suggests that the surface area does not significantly impact the photocatalytic activity.

UV-Vis DRS of LaNbON 2 synthesized by the ammonothermal method and the conventional method are shown in Figure 4 . The absorption edge of ammonothermally synthesized $\mathrm{LaNbON}_{2}$ is at ca. $710 \mathrm{~nm}$, which was not significantly changed by doping. This result suggests that doping does not significantly affect the band gap of $\mathrm{LaNbON}_{2}$.

The absorption edge of $\mathrm{LaNbON}_{2}$ synthesized by the conventional method is slightly shorter wavelength compared to ammonothermally synthesized $\mathrm{LaNbON}_{2}$. In case of oxynitride, it has been reported that absorption edge of

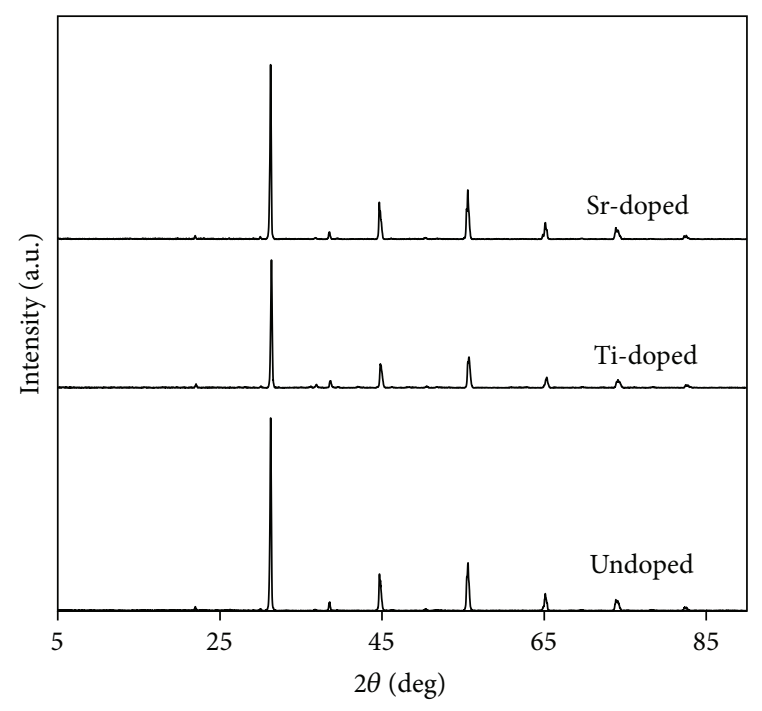

FIGURE 2: XRD patterns of lower valence cation-doped and undoped $\mathrm{LaNbON}_{2}$ synthesized by the ammonothermal method.

oxynitride is red-shift with increasing of nitrogen content in the oxynitride [16]. It is considered that ammonothermal synthesis led to higher nitrogen content in $\mathrm{LaNbON}_{2}$ compared to conventional method. However, it has been reported that crystallinity and particle morphology affect the optical properties of oxide $[17,18]$. Because of differences in crystallinity and particle morphology of products synthesized by ammonothermal and conventional method, it is difficult to consider chemical composition of product from optical properties.

Figure 5 shows the time course of hydrogen evolution from an aqueous methanol solution over undoped, Sr-doped, and Ti-doped $\mathrm{LaNbON}_{2}$ synthesized using the ammonothermal method with a Pt cocatalyst under visible light $(\lambda>$ $380 \mathrm{~nm}$ ). In the case of undoped $\mathrm{LaNbON}_{2}$, only nitrogen evolution was observed, which is presumably due to the oxidation of $\mathrm{N}^{3-}$ species near the $\mathrm{N}_{2}$ surface. This selfdecomposition has been observed for other (oxy)nitride photocatalysts during water splitting reactions [4, 19-21]. However, no hydrogen evolution was observed in our study. In the case of Sr-doped and Ti-doped $\mathrm{LaNbON}_{2}, 0.03 \mu \mathrm{mol} / \mathrm{h}$ of hydrogen evolution was observed after $3 \mathrm{~h}$.

In case of doped $\mathrm{LaNbON}_{2}$ synthesized using conventional method, only evolution of nitrogen and oxygen was observed, which is presumably due to the self-decomposition of the photocatalyst. However, no hydrogen evolution was observed. This difference is probably due to the higher crystallinity of ammonothermally synthesized $\mathrm{LaNbON}_{2}$. Thus, we successfully produced photocatalytic activity in $\mathrm{LaNbON}_{2}$ for hydrogen evolution under visible light as a result of combination with the ammonothermal synthesis and doping with lower-valence cations. The crystallinity, morphology, and absorption edge of $\mathrm{LaNbON}_{2}$ synthesized by ammonothermal method, that is, the factors possibly affecting photocatalysis, were not significantly changed by doping with a lower-valence cation. Nevertheless, the doped $\mathrm{LaNbON}_{2}$ synthesized using the ammonothermal method 


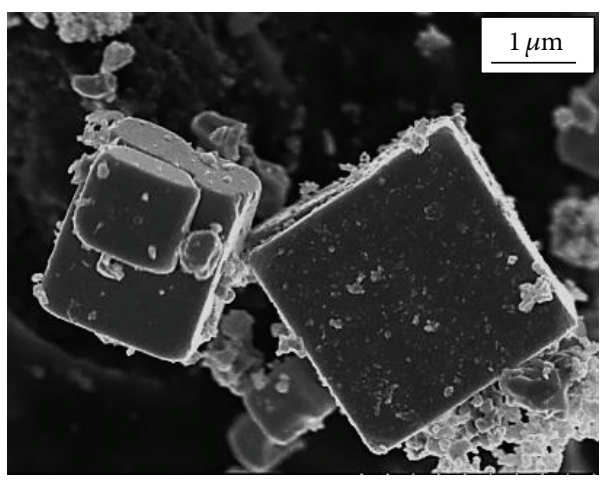

(a)

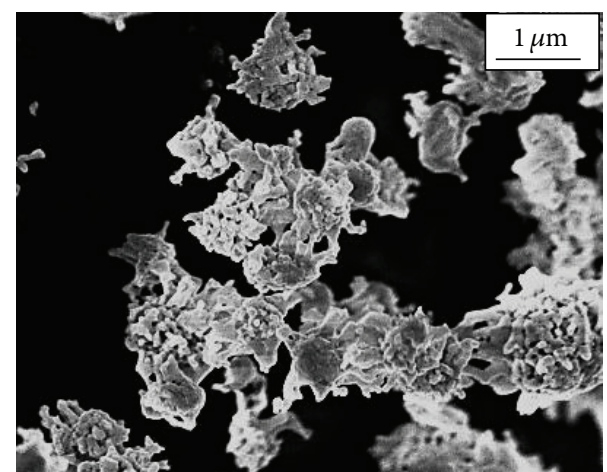

(b)

FIGURE 3: SEM images of $\mathrm{LaNbON}_{2}$ synthesized by the ammonothermal method (a) and by nitridation of an oxide precursor (b).

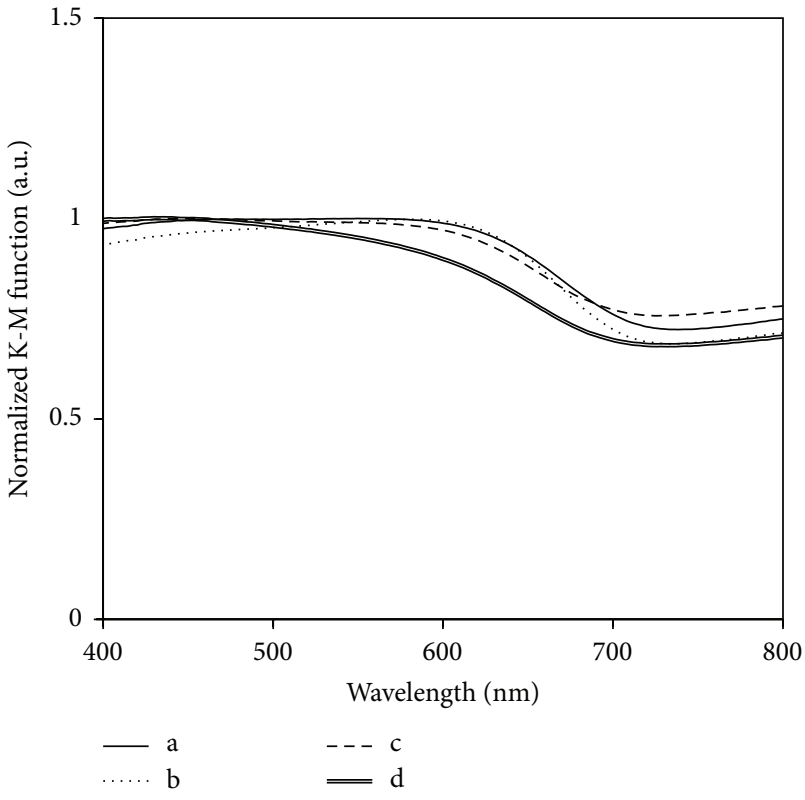

Figure 4: UV-Vis diffuse reflectance spectra of $\mathrm{LaNbON}_{2}$ synthesized by the ammonothermal method and the conventional method. (a) Undoped, (b) Sr-doped, (c) Ti-doped $\mathrm{LaNbON}_{2}$ synthesized by the ammonothermal method, and (d) $\mathrm{LaNbON}_{2}$ synthesized by the conventional method.

evolved hydrogen, suggesting that this type of doping decreases the formation of reduced niobium species and consequently enhances the photocatalytic activity of $\mathrm{LaNbON}_{2}$. Hydrogen evolution was observed in both cases after an induction period in which Pt was deposited by photogenerated electrons that would otherwise have been consumed by the reduction of water. However, two of the three products ammonothermally synthesized under the same conditions showed photocatalytic activity for hydrogen evolution.

\section{Conclusion}

We report the successful synthesis of highly crystalline perovskite-type $\mathrm{LaNbON}_{2}$ in supercritical ammonia using

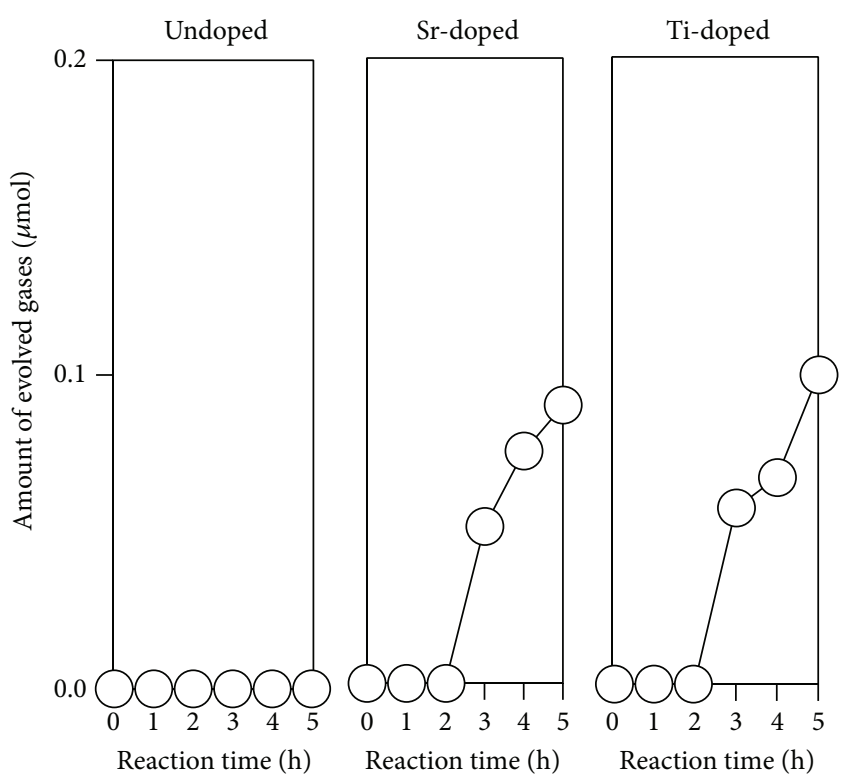

FIgURE 5: Time course of hydrogen evolution from an aqueous methanol solution over undoped, Sr-doped, and Ti-doped $\mathrm{LaNbON}_{2}$ synthesized by ammonothermal reactions with $1 \mathrm{wt} . \% \mathrm{Pt}$ cocatalyst loading under visible light $(\lambda>380 \mathrm{~nm})$.

sodium hydroxide as an oxygen source. The $\mathrm{LaNbON}_{2}$ powder synthesized by the ammonothermal reaction consists of dispersed cubic particles that reflect the high crystallinity. The crystallinity, morphology, and absorption edge of $\mathrm{LaNbON}_{2}$, the factors possibly affecting photocatalysis, were not significantly changed by doping with lower-valence cations. Nevertheless, the doped $\mathrm{LaNbON}_{2}$ synthesized using the ammonothermal method evolved hydrogen, suggesting that this type of doping decreases the formation of reduced niobium species and consequently enhances the photocatalytic activity of $\mathrm{LaNbON}_{2}$. In case of doped $\mathrm{LaNbON}_{2}$ synthesized using conventional method, no hydrogen evolution was observed. Therefore, we successfully produced $\mathrm{LaNbON}_{2}$ with improved potential for photocatalytic activity for hydrogen evolution under visible light using ammonothermal synthesis and doping with cations of lower valence than that 
of the parent cation. To the best of our knowledge, there are no reports as yet for hydrogen evolution under visible light over LaNbON $\mathrm{L}_{2}$. Verifying the reproducibility of the synthesis requires further investigation.

\section{Conflict of Interests}

The authors declare that there is no conflict of interests regarding the publication of this paper.

\section{References}

[1] K. Takanabe and K. Domen, "Preparation of inorganic photocatalytic materials for overall water splitting," ChemCatChem, vol. 4, no. 10, pp. 1485-1497, 2012.

[2] K. Maeda and K. Domen, "Oxynitride materials for solar water splitting," MRS Bulletin, vol. 36, no. 1, pp. 25-31, 2011.

[3] K. Maeda and K. Domen, "New non-oxide photocatalysts designed for overall water splitting under visible light," The Journal of Physical Chemistry C, vol. 111, no. 22, pp. 7851-7861, 2007.

[4] B. Siritanaratkul, K. Maeda, T. Hisatomi, and K. Domen, "Synthesis and photocatalytic activity of perovskite niobium oxynitrides with wide visible-light absorption bands," ChemSusChem, vol. 4, no. 1, pp. 74-78, 2011.

[5] D. Logvinovich, S. G. Ebbinghaus, A. Reller, I. Marozau, D. Ferri, and A. Weidenkaff, "Synthesis, crystal structure and optical properties of $\mathrm{LaNbON}_{2}$," Zeitschrift für Anorganische und Allgemeine Chemie, vol. 636, no. 6, pp. 905-912, 2010.

[6] N.-Y. Park and Y.-I. Kim, "Morphology and band gap variations of oxynitride $\mathrm{LaTaON}_{2}$ depending on the ammonolysis temperature and precursor," Journal of Materials Science, vol. 47, no. 13, pp. 5333-5340, 2012.

[7] M. Liu, W. You, Z. Lei, T. Takata, K. Domen, and C. Li, "Photocatalytic water splitting to hydrogen over a visible lightdriven $\mathrm{LaTaON}_{2}$ catalyst," Chinese Journal of Catalysis, vol. 27, no. 7, pp. 556-558, 2006.

[8] R. Aguiar, D. Logvinovich, A. Weidenkaff, A. Rachel, A. Reller, and S. G. Ebbinghaus, "The vast colour spectrum of ternary metal oxynitride pigments," Dyes and Pigments, vol. 76, no. 1, pp. 70-75, 2008.

[9] S. Ikeda, N. Sugiyama, S.-Y. Murakami et al., "Quantitative analysis of defective sites in titanium(IV) oxide photocatalyst powders," Physical Chemistry Chemical Physics, vol. 5, no. 4, pp. 778-783, 2003.

[10] D. Ehrentraut, Y. Kagamitani, T. Fukuda et al., "Reviewing recent developments in the acid ammonothermal crystal growth of gallium nitride," Journal of Crystal Growth, vol. 310, no. 17, pp. 3902-3906, 2008.

[11] J. Li, T. Watanabe, H. Wada, T. Setoyama, and M. Yoshimura, "Low-temperature crystallization of eu-doped red-emitting $\mathrm{CaAlSiN}_{3}$ from alloy-derived ammonometallates," Chemistry of Materials, vol. 19, no. 15, pp. 3592-3594, 2007.

[12] T. Watanabe, K. Nonaka, J. W. Li, K. Kishida, and M. Yoshimura, "Low temperature ammonothermal synthesis of europiumdoped $\mathrm{SrAlSiN}_{3}$ for a nitride red phosphor," Journal of the Ceramic Society of Japan, vol. 120, no. 1407, pp. 500-502, 2012.

[13] T. Watanabe, K. Tajima, J. Li, N. Matsushita, and M. Yoshimura, "Low-temperature ammonothermal synthesis of $\mathrm{LaTaON}_{2}$," Chemistry Letters, vol. 40, no. 10, pp. 1101-1102, 2011.
[14] T. Takata and K. Domen, "Defect engineering of photocatalysts by doping of aliovalent metal cations for efficient water splitting," The Journal of Physical Chemistry C, vol. 113, no. 45, pp. 19386-19388, 2009.

[15] M. Jansen and H. P. Letschert, "Inorganic yellow-red pigments without toxic metals," Nature, vol. 404, no. 6781, pp. 980-982, 2000.

[16] T. Moriga, D. Aoki, Y. Nishida et al., "Blue-shift of absorption edge in $\mathrm{LaTiO}_{2} \mathrm{~N}$ by controlling the anion nonstoichiometry," Physica Status Solidi (A), vol. 203, no. 11, pp. 2818-2822, 2006.

[17] H. Song, T. Peng, P. Cai, H. Yi, and C. Yan, "Hydrothermal synthesis of flaky crystallized $\mathrm{La}_{2} \mathrm{Ti}_{2} \mathrm{O}_{7}$ for producing hydrogen from photocatalytic water splitting," Catalysis Letters, vol. 113, no. 1-2, pp. 54-58, 2007.

[18] F. M. Pontes, C. D. Pinheiro, E. Longo et al., "The role of network modifiers in the creation of photoluminescence in $\mathrm{CaTiO}_{3}$," Materials Chemistry and Physics, vol. 78, no. 1, pp. 227-233, 2003.

[19] G. Hitoki, T. Takata, J. N. Kondo, M. Hara, H. Kobayashi, and K. Domen, "(Oxy)nitrides as new photocatalysts for water splitting under visible light irradiation," Electrochemistry Communications, vol. 70, no. 6, pp. 463-465, 2002.

[20] K. Maeda, K. Teramura, N. Saito, Y. Inoue, and K. Domen, "Photocatalytic overall water splitting on Gallium nitride powder," Bulletin of the Chemical Society of Japan, vol. 80, no. 5, pp. 10041010, 2007.

[21] A. Kasahara, K. Nukumizu, G. Hitoki et al., "Photoreactions on $\mathrm{LaTiO}_{2} \mathrm{~N}$ under visible light irradiation," Journal of Physical Chemistry A, vol. 106, no. 29, pp. 6750-6753, 2002. 

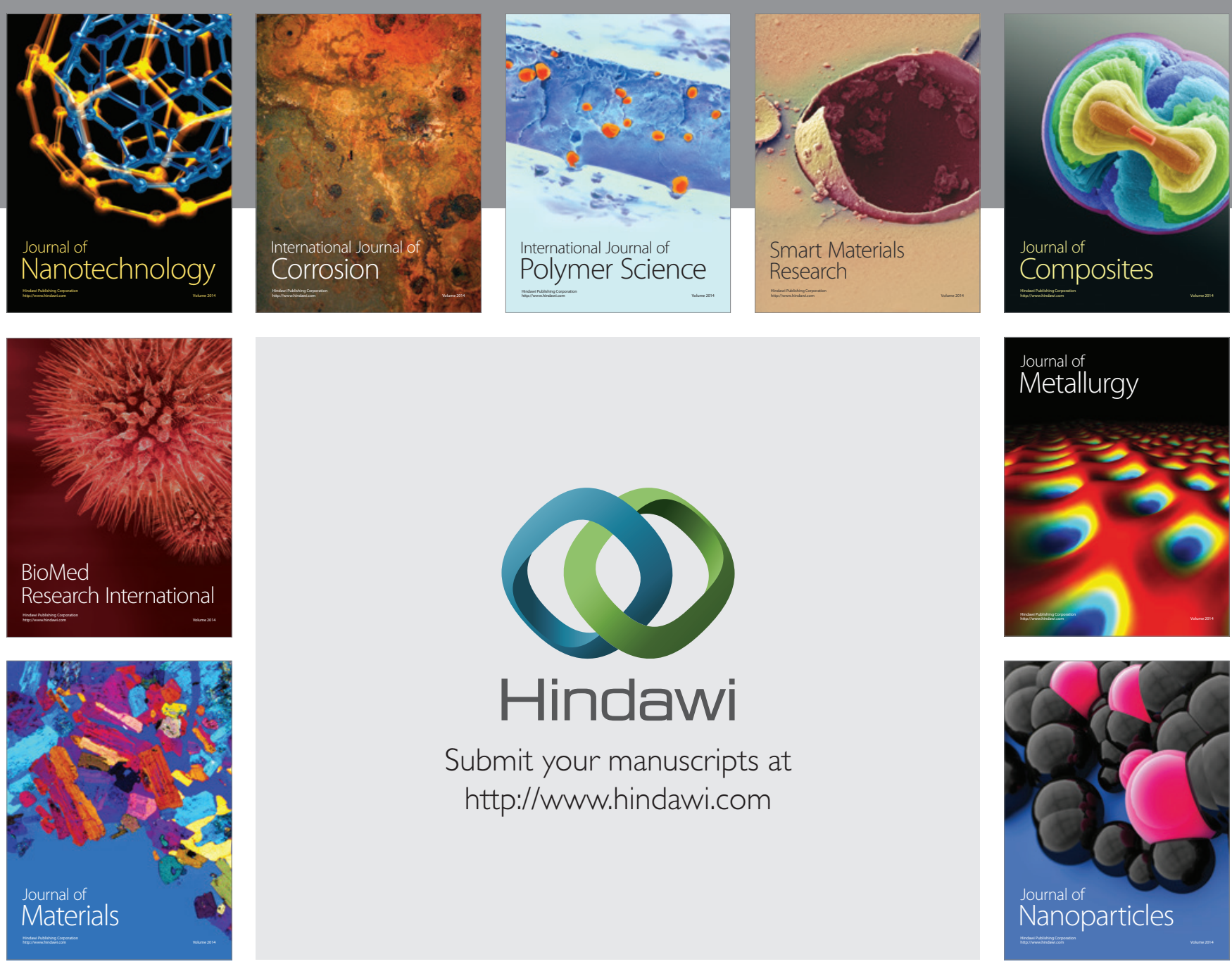

Submit your manuscripts at http://www.hindawi.com
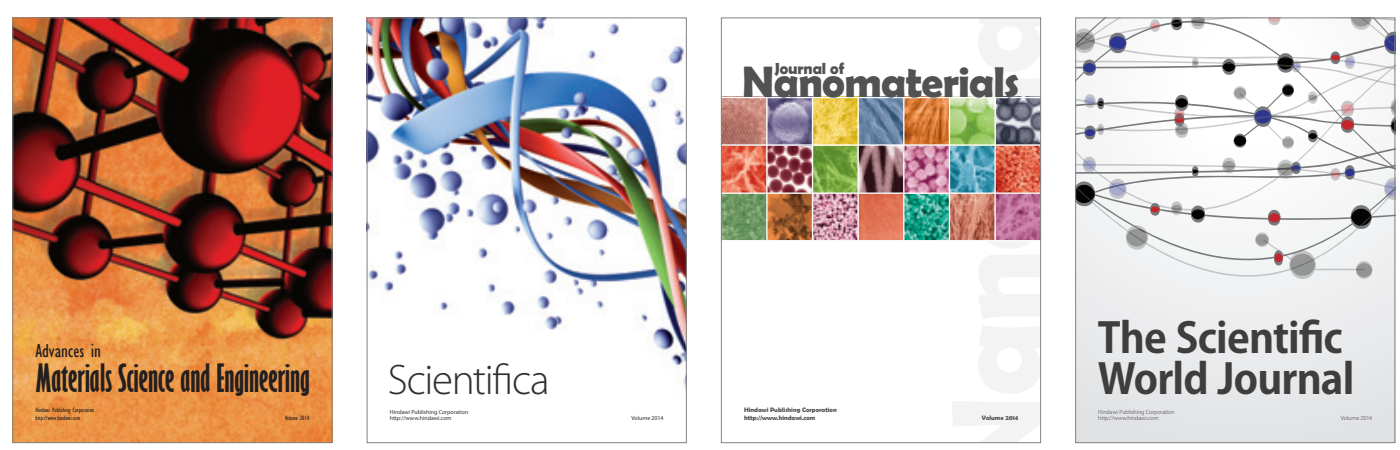

\section{The Scientific World Journal}
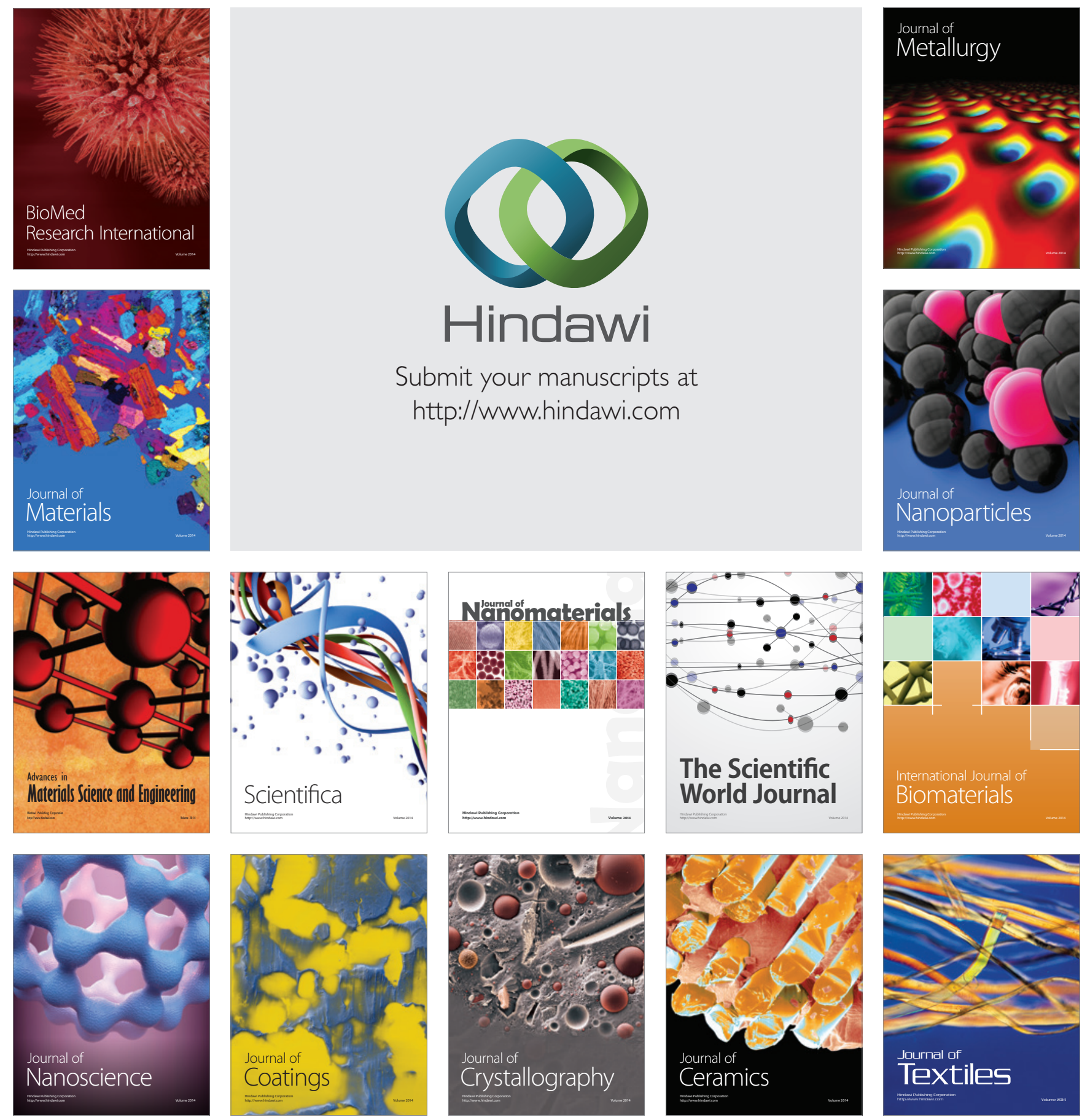